\title{
LIKE, TWEET, OR PIN: COLLEGE STUDENTS AND THEIR CURRENT USE OF SOCIAL MEDIA
}

\author{
Gayle R. Jesse, Thiel College, gjesse@thiel.edu
}

\begin{abstract}
Social Media (SM) is ever-present in the daily "online" life of an individual and ultimately offers a platform for individuals and businesses to interact and communicate. Facebook continues to be the most popular social media site [2]; however, the use of Twitter and Pinterest is on the rise. Social Networking Sites (SNS) provide individuals, especially college students, an outlet to share a wealth of information. Yet, questions arise: are college students still spending as much time using Facebook? Is Facebook still college students' first choice in SM or have they switched to Twitter and Pinterest? The purpose of this study is to determine if college students are using SM as much as they were two-and-a-half years ago. Discerning the answer to these research questions involved comparing data collected from a Fall 2010 dissertation study to survey data collected during the Spring 2013 semester. The findings of this explanatory study were significant: social media usage among college students has increased in two-and-a-half years, certain demographics influence SM usage and Facebook usage has declined by $38 \%$, which suggests students are seeking and using other SM technologies.
\end{abstract}

Keywords: Social Media, Social Networking Sites, College Students, Facebook, Twitter and Pinterest

\section{INTRODUCTION}

Many assume that a typical college student's life involves an almost daily and permanent connection to Facebook. However, after engaging Thiel College students in open discussions about Facebook usage, that assumption may not hold true. Moreover, it may be possible that college students are now using Facebook less because their parents and grandparents do, and students are largely using Twitter and Pinterest. In the March 22, 2013 edition of The Thielensian, Thiel College's newspaper, student Sara Toombs offered an inside look at college students' views on social media in an article titled "Toombs Time: A Facebook-free Life." Toombs [14] writes,

"Oh that's right, you don't have Facebook."

I cannot claim to be one of those trend-fighting heroines who have never succumbed to the temptation of social networking. I had a MySpace when that was cool, I made a Facebook when that became the fad, and I social networked with the best of them for the majority of my teen years. However, this year, I decided to delete my Facebook. It seemed like an innocent act, and deactivating my page was simply my way of "decongesting" my life, but the social repercussions of being a non-Facebook user have astounded me.

I have missed countless party invitations, new baby photos, and birthdays, and I have had to ask "Wait, who is dating whom?" more times than I am proud of. And everyone is so surprised at how misinformed I truly am. But, the fact of the matter is, no one verbally tells each other those things anymore. In a world with Facebook, there is no need to ask someone to an event in person, no need to actually introduce them to your newborn, or even tell anyone when you were born. It's okay - they will see it on Facebook.

The moral of this story could easily be that times are changing, and that having social networking profiles is simply a new necessity of communication. I, however, am going to have to refuse this doctrine because I absolutely love life without Facebook. I have found that I concern myself so much less with others' drama, I avoid the constant stream of pictures taken from bathroom mirrors, and I actually rely on face-to-face conversations (or at least phone calls) with people to obtain information. For some reason, learning from Suzie $Q$. over lunch that she is going steady with Joe Schmo just feels so much more social than a blip on a smart phone that says "Suzie $Q$. is in a relationship... and it's complicated."

I completely approve of the benefits that Facebook brings; networking of any kind is very beneficial to personal and career development if done in the appropriate way. My only grief with Facebook is its ability to replace the flow of normal conversation between friends. Someone I went to high school with told me the other day, "I miss when you had Facebook. I knew so much more about your life." I responded, "Well, why don't you call and ask me about it?" She honestly replied, "I didn't think of that." 


\section{Issues in Information Systems \\ Volume 14, Issue 1, pp.403-414, 2013}

So, while I am in no way advocating that everyone immediately delete their Facebook's and revert to the life of a "networking hermit," I am encouraging FB users to remember the limits of an Internet profile. Reading about someone on a wall just doesn't feel as cozy as the sound of their actual voice (p. 4).

Toombs' [14] article prompted this research to build on a Fall 2010 study of Thiel College students. In the previous study, I conducted a college-wide survey of Thiel College students and their SNS use as part of my dissertation titled, The Influence of Personality on the Type of Information College Students Share on Social Networking Sites.

\section{BACKGROUND}

\section{Definitions of Social Networking}

The terms Social Media (SM) and Social Networking Sites (SNS) will be used interchangeably throughout this paper. However, each term must be defined. According to Ahlqvist, Bäck, Halonen, \& Heinonen [1], social media (SM) is an umbrella term describing the means of interactions among people in which they create, share, and exchange information and ideas in virtual communities and networks. Boyd [3] defines social networking sites (SNS) as sites that share the following technical features:

1. Construct a public/semi-public profile.

2. Articulate a list of other users with whom they share a connection.

3. View their list of connections within the system.

Additionally, Boyd and Ellison [4] adopt Sunden's [13] description of profiles as unique pages where one can "type oneself into being." Boyd and Ellison [4] state that a profile is generated from answers to questions, such as age, location, interests, and other demographic data. Furthermore, some SNS allow users to upload pictures, list social links, add multimedia content, modify the look and feel of the profile, post blog entries, search for others with similar interests, compile and share contacts, and maintain a section dedicated to comments from other users. Others SNS, such as Facebook, allow users to enhance their profiles by adding modules or "Applications." [4]

\section{History of Social Networking}

Appendix A contains a timeline of major SNS from 1997 to 2006. In addition to the timeline, further research found that according to Boyd and Ellison [4], in 1997 SixDegrees.com allowed users to create profiles, list their friends and, in 1998, surf the friends lists. SixDegrees.com was the first to combine all three SNS technical features [4]. Some earlier SNS users did have the capability to create a profile; however, other SNS did not have the capability to create profiles or list Friends until years later and even then the friends were not visible to others.

\section{Social Networking Site Usage}

Social media is an Internet phenomenon and the popularity of SNS continues to rise; however, as technology continues change, so, too, does the way individuals use SM. Alexa.com [2], ranks the top five SNS as follows:

1. Facebook;

2. Twitter;

3. LinkedIn;

4. Google+;

5. Pinterest.

Facebook, Twitter and Pinterest operate under the concept of what is called real-time web. Leggetter [10] defines real-time web as searching for and finding information online as it is produced. Real time web has the ability to deliver the most popular topics recently discussed or posted by users. Leggetter [10] further states, "the content is often 'soft' in that it is based on the 'social web' - people's opinions, attitudes, thoughts and interests - as opposed to hard news or facts." Real-time web is information or content that is normally short messages, status updates, news alerts, or links to longer documents on the social web. Real-time web allows users to contribute content, which is then broadcast as it is being uploaded. 


\section{Issues in Information Systems \\ Volume 14, Issue 1, pp.403-414, 2013}

Twitter is the second most popular SNS and was the first use start real-time web services in March 2006 [15]. At the heart of Twitter are small bursts of information called Tweets, and each Tweet is 140 characters long [15]. Twitter allows the user to see photos, videos and conversations directly in Tweets to get the whole story at a glance and all in one place. Facebook, the top ranked SNS, followed Twitter and developed News Feed and Live Feed, which are meant to balance one another. For example, Facebook's home page provides two views to help users connect with family and friends: News Feed is a summary view of your friends' activity, whereas Live Feed is the real-time web view that is continuously updated. The average Facebook user normally reads the News Feed first and then the Live Feed keeps the users simultaneously updated. Additionally, Pinterest, the fifth-ranked SNS, is an image-based social media network. According to Pinterest.com [12], "Pinterest is a tool for collecting and organizing things you love." Individuals can browse boards created by others to discover new ideas and be inspired by people who share their same interests; individuals use boards to plan trips, decorate homes, and share recipes. On Pinterest's Pinning 101 page [12], there are six basic functions: Pin, Board, Follow, Unfollow, Pin It Bookmarklet, and Home Feed.

The background information of this paper aimed to provide foundational definitions, history, and current social media usage. A survey of literature available on the comparisons of SNS usage suggests a gap within the current research. Thus, it is important to follow the trends of such a phenomenon and report current statistical data.

\section{METHODOLOGY}

\section{Research Design}

This explanatory study was designed utilizing quantitative methods. Conducting this quantitative study involved administering a survey in three phases. The first phase consisted of developing a survey instrument based upon the initial 2010 survey. The second phase included testing with a pilot study involving one Thiel College student to determine the time needed to complete the survey. Finally, the third phase entailed distribution to traditional college-aged Thiel College students. The survey research maintained an objective approach. Three software products were used: Moodle Learning Management System, SurveyMonkey, and Microsoft Excel.

\section{Participants}

The target population for this study was Thiel College as a convenience sample. Thiel College is a small, four-year Lutheran-based liberal arts institution located in western Pennsylvania. Table 1 provides the Fall 2010 and Spring 2013 enrollment statistics: the response rate was approximately $30 \%$ for each semester.

Table 1. Participation Statistics

\begin{tabular}{|l|r|r|}
\hline & Fall 2010 & Spring 2013 \\
\hline Total Enrollment & 950 & 981 \\
\hline Consent Agreement \& $>18$ years old & 326 & 291 \\
\hline Percent of Thiel College population & $\mathbf{3 4 \%}$ & $\mathbf{3 0 \%}$ \\
\hline
\end{tabular}

Survey participants were volunteers who responded though Moodle and professor recruitment. To be eligible, participants needed to be over 18-years-old and enrolled at Thiel College. Engaging the entire Thiel College population to participate reflected a true representation of the college's student body across multiple majors and their views on social networking actions.

\section{Instruments/Data Collection Tools}

The survey was conducted via surveymonkey.com. The survey instrument developed for this study was derived from multiple sources and included both validated and non-validated questions. The initial survey was divided into the following six sections:

1. Consent Form;

2. Demographic Information;

3. Social Media;

4. Smart Phones; 


\section{Issues in Information Systems \\ Volume 14, Issue 1, pp.403-414, 2013}

5. $\quad$ E-Readers \& E-Textbooks;

6. Thank you.

While the survey covered three main sections, Social Media, Smart Phones, and E-Readers \& E-Textbooks, only the Social Media results are considered in this paper.

\section{RESEARCH QUESTIONS}

College students' preferred SNS, most used SNS, the number of visits to their SNS, and the amount of time spent on SNS is continuously changing. The two objectives of this study were to determine if Thiel College students are still using Facebook as a primary SNS, and if students are spending as much time on SNS as they were in 2010. The information and research presented in the Background section, in conjunction with the administration of a survey described in the Methodology section, help answer the Research Questions (RQ).

\section{Research Questions}

The overall intent of this study is to determine if college students are still using Facebook as a primary SNS and if they are spending as much time on SNS as they were in 2010. The research questions to be answered and hypotheses to be tested are as follows:

RQ1: What percentage of college students currently has a SNS account?

RQ2: What percentage of college students had a SNS account in high school?

RQ3: How often do college students visit SNS?

RQ4: How much time do college students spend on SNS?

RQ5: How much time do computer science students spend on SNS?

RQ6: How often do computer science majors visit their SNS?

RQ7: To what extent do demographics influence time spent using SM?

H1: Students 20 years of age and below spend more time on SNS than students over 20 years old.

H2: Female students spend more time on SNS than males.

H3: Students with a GPA less than 3.0 spend more time on SNS than students with a GPA of 3.0 or greater.

H4: Students majoring in communications spend more time on SNS than all other majors.

\section{DATA ANALYSIS AND DISCUSSION}

Microsoft Excel software was used to calculate the statistical data. The following quantitative results were obtained to answer the seven research questions; all percentage results exclude the system missing responses. Appendix B contains the demographic statistics of age, gender, race, GPA, and college majors reported in 2010 and 2013.

RQ1: What percentage of college students currently have a social networking account? Table 2 shows a consistent percentage of Thiel College students who currently have a social networking account in 2010 and 2013.

Table 2. RQ1: Percentage of college students who currently have a social networking account

Do you ever use the Internet to use a social networking site (SNS)? (MySpace, Facebook or LinkedIn.com) 


\section{Issues in Information Systems}

Volume 14, Issue 1, pp.403-414, 2013

\begin{tabular}{|l|r|r|}
\hline Yes & $97 \%$ & $97 \%$ \\
\hline No & $3 \%$ & $3 \%$ \\
\hline
\end{tabular}

Students in 2010 provided the following reasons why they did not have a social networking account: security and privacy issues, fear of loss of confidentiality, don't want to be bothered by people I really do not know well, and ruins your life. Furthermore, the 2013 study found that $67 \%$ of students use Twitter and 39\% use Pinterest. Students also noted other SNS used: Instagram (19 students), Meet Me - formerly myYearbook (2), Tumblr (6), Snapchat (2), LinkedIn (1), Oovoo (1), Skype (1).

RQ2: What percentage of college students had a social networking account in high school? Table 3 displays the percentage of Thiel College students that had a social networking account in high school in both 2010 and 2013. Results show a 10\% increase. Students that chose another SNS listed MySpace (10 students), Tumblr (3) and school social network (1).

Table 3. RQ2: Percentage of college students who had a SN account in high school

\begin{tabular}{|l|r|r|}
\hline Did you have a social networking site account in high school? & $\mathbf{2 0 1 0}$ & $\mathbf{2 0 1 3}$ \\
\hline Yes & $77 \%$ & $\mathbf{8 7 \%}$ \\
\hline No & $\mathbf{2 1 \%}$ & $13 \%$ \\
\hline Not sure & $2 \%$ & \\
\hline
\end{tabular}

RQ3: How often do college students visit SNS? Table 4 illustrates how often Thiel College students visit their most used social networking account. The option "several times a day" rose 6\%; however, "about once a day" decreased 5\%. Additionally, about 7\% visit their SNS "every few days" which had risen 2\% from 2010.

Table 4. RQ3: Percentage of college students who visit social networking sites (SNS)

\begin{tabular}{|l|r|r|}
\hline $\begin{array}{l}\text { How often do you visit the social networking web site where you have a profile/the social } \\
\text { networking web site with the profile you use MOST OFTEN? }\end{array}$ & $\mathbf{2 0 1 0}$ & $\mathbf{2 0 1 3}$ \\
\hline Several times a day & $71 \%$ & $\mathbf{7 7 \%}$ \\
\hline About once a day & $\mathbf{1 9 \%}$ & $14 \%$ \\
\hline Every few days & $5 \%$ & $\mathbf{7 \%}$ \\
\hline Once a week & $1 \%$ & $0 \%$ \\
\hline Less often & $\mathbf{5 \%}$ & $2 \%$ \\
\hline
\end{tabular}

RQ4: How much time do college students spend on SNS? Table 5 highlights the amount of time Thiel College students spend using SNS. The time frame "less than 30 minutes" dropped 15.1\%; however, all other time categories increased in percentage of use. The largest increase was $8.1 \%$ in the $2-3$ hours a day category.

Table 5. RQ4: Time college students spend on SNS

\begin{tabular}{|l|r|r|r|}
\hline $\begin{array}{l}\text { In a typical day, about how much time do you spend using social networking } \\
\text { websites? }\end{array}$ & $\mathbf{2 0 1 0}$ & $\mathbf{2 0 1 3}$ & $\begin{array}{c}\text { \% } \\
\text { Increase }\end{array}$ \\
\hline Less than 30 minutes & $\mathbf{4 7 . 6 \%}$ & $32.5 \%$ & $-15.1 \%$ \\
\hline 30 - 60 minutes & $16.2 \%$ & $\mathbf{2 2 . 8 \%}$ & $6.6 \%$ \\
\hline $1-1.5$ hours & $4.0 \%$ & $\mathbf{1 1 . 4 \%}$ & $7.4 \%$ \\
\hline $1.5-$ hours & $7.4 \%$ & $\mathbf{1 2 . 1 \%}$ & $4.7 \%$ \\
\hline 2 - 3 hours & $2.5 \%$ & $\mathbf{1 0 . 6 \%}$ & $8.1 \%$ \\
\hline 3 - 4 hours & $1.8 \%$ & $\mathbf{6 . 6 \%}$ & $4.8 \%$ \\
\hline More than 4 hours & $2.7 \%$ & $\mathbf{4 . 0} \%$ & $1.3 \%$ \\
\hline
\end{tabular}

For RQ5 and RQ6, 20 computer science students completed the survey, which is $6.9 \%$ of the total participants or $2 \%$ of Thiel College's Spring 2013 enrollment. Computer science students included the following declared majors: Computer Science, Management Information Systems, and Web Development. Additionally, the analyzed data is only from the 2013 survey. 


\section{Issues in Information Systems \\ Volume 14, Issue 1, pp.403-414, 2013}

RQ5: How much time do computer science students spend on SNS? Table 6 displays the percentage of time computer science students spend on SNS. The data below conveys that $45 \%$ or 9 out of 20 students spend less than 30 minutes per day, while $20 \%$ or 4 students spend $1.5-2$ hours per day.

Table 6. RQ5: Time computer science students spend on SNS

\begin{tabular}{|l|r|}
\hline \multicolumn{2}{|l|}{$\begin{array}{l}\text { How much time do computer science } \\
\text { students spend on SNS? }\end{array}$} \\
\hline$<30$ minutes & $45 \%$ \\
\hline $46-60$ minutes & $10 \%$ \\
\hline $1-1.5$ hours & $10 \%$ \\
\hline $1.5-2$ hours & $20 \%$ \\
\hline $2-2.5$ hours & $10 \%$ \\
\hline $3-3.5$ hours & $5 \%$ \\
\hline
\end{tabular}

RQ6: How often do computer science majors visit their SNS? Table 7 demonstrates how often computer science students visit their SNS. The data indicates that $80 \%$ of computer science students visit their SNS several times a day and $15 \%$ visit at least once a day, which means $95 \%$ of computer science students visit their SNS once a day.

Table 7. RQ6: Computer science majors visit SNS

\begin{tabular}{|l|r|}
\hline \multicolumn{2}{|l|}{ How often do Computer Science } \\
majors visit there SNS? \\
\hline several times a day & $80 \%$ \\
\hline once a day & $15 \%$ \\
\hline every few days & $5 \%$ \\
\hline
\end{tabular}

RQ7 contains four hypotheses that will be answered in this research study. RQ7 is: To what extent do demographics influence time spent using social media?

H1: Students below the age of 20 spend more time on SNS than students over 20 years old. The percentage of participants equal to or less than 20 years of age was $71 \%$ or a count of 208 , and participants over 20 years old was $29 \%$ or a count of 85 . The result of $\mathrm{H} 1$ is that a prediction can be made that college students that are less than or equal to 20 years old spend more time on SNS.

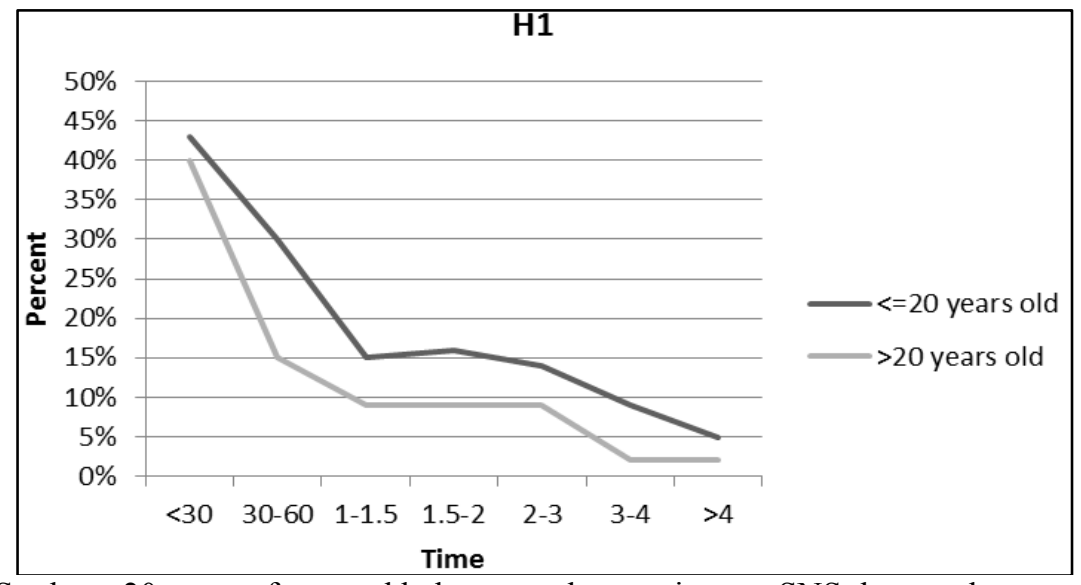

Figure 1. H1: Students 20 years of age and below spend more time on SNS than students over 20 years old.

H2: Female students spend more time on SNS than males. The result of $\mathrm{H} 2$ finds that $41 \%$ of male participants spent less than 30 minutes a day on SNS and after 30 minutes the percentage fell below 10\%. However, the percentage of females spending more than 30 minutes is greater than males and remains greater over the remaining time categories; thus, a prediction can be made that females spend more time on SNS than males. 


\section{Issues in Information Systems}

Volume 14, Issue 1, pp.403-414, 2013

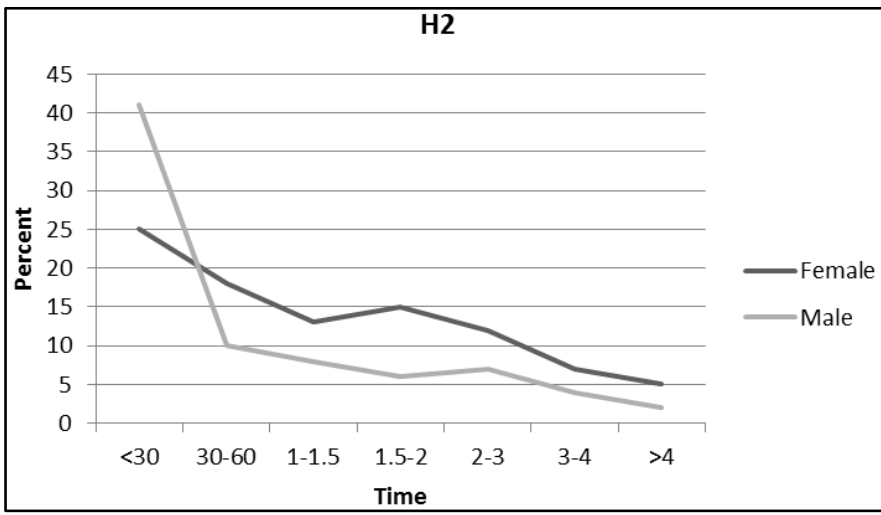

Figure 2. H2: Female students spend more time on SNS than males.

H3: Students with a GPA less than 3.0 spend more time on SNS than students with a GPA of 3.0 or greater.. The number of participants with GPAs less than 3.0 was $26 \%$ (73 students), while $74 \%$ of respondents ( 210 students) had GPAs equal to or greater than 3.0. The result of H3 predicts that college students with GPAs lower than a 3.0 spend more time on SNS than students with GPAs over 3.0.

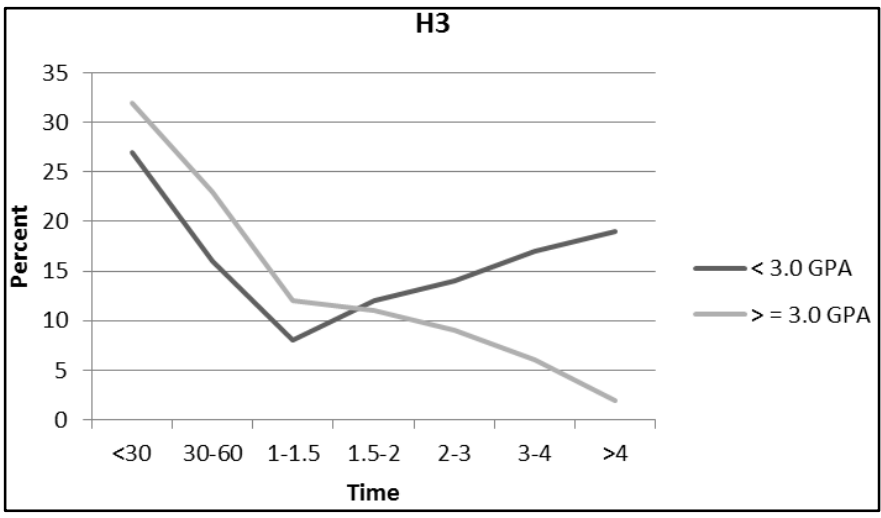

Figure 3. H3: Students with a GPA less than 3.0 spend more time on SNS than students with a GPA of 3.0 or greater.

H4: Students majoring in communications spend more time on SNS than other majors. Seventeen students, 6\% of participants, were communications majors. The total of all other majors was 271 , or $94 \%$ of survey participants. The result of H4 predicts that students majoring in communications spend more time on SNS than all other college majors. Figure 4 shows this prediction for time spent between 30 minutes and 2 hours per day. 


\section{Issues in Information Systems}

Volume 14, Issue 1, pp.403-414, 2013

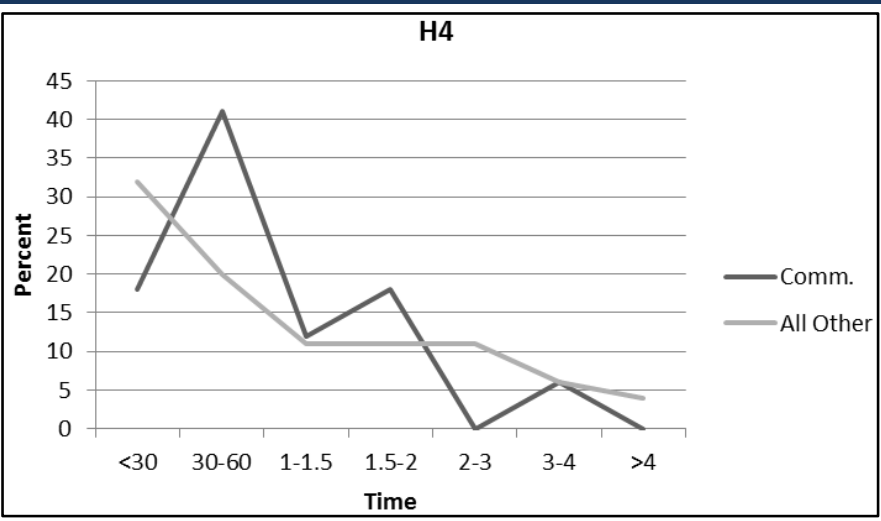

Figure 4. H4: Students majoring in communications spend more time on SNS than all other majors.

Based on the statistical analyses, we conclude that college students are actually spending more time on social media than originally hypothesized.

\section{ADDITIONAL FINDINGS}

Additional questions were asked in both the 2010 and 2013 surveys that did not relate to time spent using social media, but were related to profiles, favorite SNS, the effect of Facebook's shift toward businesses, a professor's use of Facebook in the classroom, and texting while a professor is teaching.

\section{Profiles}

The 2010 survey asked: How many total profiles (on social networking websites) do you have online, counting ALL websites? Participants responded that $43 \%$ have only one profile, $41 \%$ have two profiles, $9 \%$ have 3 profiles, and $3 \%$ for both 4 and 5 profiles. The survey provided a list option if respondents had more than 6 profiles and the three typed responses were: "more than 6 ," " 8 but only $2 / 3$ are consistently in use," and " 10 ." Additionally in 2010 , the survey asked: On which social networking website is your profile or update most often? (only the one site you use the most) and 95\% responded with Facebook, 2\% MySpace, and 1\% Yahoo! 360. Again, participants had the option to list other SNS used: Twitter (3 students), Cyworld (2) and QQ (1).

\section{Favorite SNS}

The 2013 survey asked: If you could use only one of the following social networking services, which would you use? Responses included: $57 \%$ Facebook, 34\% Twitter, 6\% Pinterest, and 3\% Google+. Students could also list their own favorite SNS: Tumblr (3 students) and Instagram (2). The results for the favorite SM site indicate that Facebook and Twitter are only separated by $23 \%$ as the top choice. More importantly, if comparing the 2010 survey question (On which social networking website is your profile or update most often? Only one site you use the most) to the 2013 question, Facebook's top position fell $38 \%$, from $95 \%$ to $57 \%$. Thus, a prediction can be made that Facebook preference is declining among college students who are switching to SM technologies such as Twitter and Pinterest.

\section{Business Use}

Several questions were included to determine what Thiel College students thought about Facebook's shift to business. The survey asked: If you use Facebook...Do you like the fact that Facebook is catering/turning/shifting more into a social media site for businesses and/or investors? Thiel students responded as follows: only $26 \%$ liked the shift, $31 \%$ did not like shift, and $43 \%$ said they were "not sure/undecided," which could mean that they did not realize that Facebook had shifted focus toward businesses. When asked Has this business shift affected your use of Facebook? 5\% responded their use had increased, 20\% indicated their use had decreased, 62\% said their use stayed the same, and $13 \%$ were "not sure/undecided."

\section{Professors and Classroom Use}




\section{Issues in Information Systems \\ Volume 14, Issue 1, pp.403-414, 2013}

As a professor, do you feel SM has a roll in the classroom? In 2012, Hurt et al., [6] built on Kirschner \& Karpinski [9] to suggest that although anti-Facebook sentiment and bias among college instructors is warranted occasionally, many students seem to view Facebook as a useful educational tool. The 2013 survey conducted at Thiel College asked students, Should professors integrate Facebook use in the classroom? The students responded: 16\% yes, $60 \%$ no, and 24\% "not sure/undecided." When asked, If your professor set up a Facebook Group for your class, do you think your student involvement and course performance would increase? [A Facebook group is way to continue class discussions, allow students to ask questions, and encourage students to post and comment on class-related links (news articles, etc.).]. 35\% of the students stated they would be more involved in class and their performance would increase, $26 \%$ would not be more involved in class, $15 \%$ have no interest in using Facebook at all for classes, and $24 \%$ are "not sure/ undecided." The data results of the survey at Thiel College are different from what Hurt et al., [6] and Junco [7] predicted. In January 2012, Junco [7] blogged that college students prefer to use Facebook in courses and faculty should integrate Facebook Group into courses. Junco [7] encouraged "faculty to actively participate in such groups to increase student involvement and improve course performance."

\section{Texting in Class}

Junco's [8] November 2012 article suggests that in the classroom environment, "texting was a high frequency activity: $69 \%$ of students reported texting during class." As a professor, I am also curious if students are texting in class, which prompted a question in the 2013 survey: Have you sent a text message from your phone (any type of phone) while the teacher was teaching in class? The response was overwhelmingly affirmative. $83 \%$ percent of the participants said yes, $15 \%$ said no, and 3\% preferred not to answer. A notable fact on texting is that $48 \%$ of $18-24-$ year-olds believe text messaging is just as meaningful as an actual conversation with a person on the phone [11].

\section{CONCLUSIONS}

As a possible avenue for future research and consideration, the 2013 survey was also conducted at Robert Morris University (RMU) located in Moon Township, Pennsylvania. A comparison study between the two institutions with a co-author from RMU is underway.

One limitation to this study was not being able to use a statistical software package such as SPSS or Minitab. A second limitation was that only one person conducted this research.

This study provided practical insights for the field of computer information systems by exploring SM use among college students. The seven research questions in this exploratory found the following statics and predictions. The findings of this study were significant.

- $\quad$ RQ1 $-97 \%$ of college students have a SN account.

- $\mathrm{RQ} 2-10 \%$ rise in the percentage of college students that had a SN account in high school.

- RQ3-6\% rise in the percentage of college students that visit their favorite SNS more than once a day.

- RQ4 - 8\% increase in spending 2-3 hours a day using SM; overall, students are spending more time on SM.

- RQ5 - 45\% of computer science students spend less than 30 minutes on SNS and 20\% spend $1.5-2$ hours.

- RQ6 - 95\% of computer science students visit their SNS once a day, $80 \%$ of computer science students visit their SNS several times a day, and $15 \%$ visit their site at least once a day.

- $\quad$ RQ7 - Do demographics influence time spent using SM?

- H1 - college students less than or equal to 20 years old spend more time on SNS then 21 and over.

- $\mathrm{H} 2$ - females spend more time on SNS than males.

- H3 - college students with GPAs lower than 3.0 spend more time on SNS than students with GPAs over 3.0.

- $\mathrm{H} 4$ - communication majors spend more time on SNS than all other college majors.

Furthermore, other significant findings were as follows:

- Profiles $-43 \%$ of college students have only one profile and $41 \%$ have two profiles.

- Favorite SNS:

○ Facebook fell from 95\% to 57\%, a decline of 38\% from 2010 to 2013. 


\section{Issues in Information Systems \\ Volume 14, Issue 1, pp.403-414, 2013}

○ In 2013, the favorite sites were: 57\% Facebook, 34\% Twitter, 6\% Pinterest, and 3\% Google+.

- Business Use $-62 \%$ said their use stayed the same since Facebook shifted to more businesses.

- Professors and Classroom Use - 60\% said "NO" to professors using Facebook in the classroom; however, if a professor did use Facebook Groups, 35\% stated they would be more involved in class and their performance would increase while $26 \%$ would not be more involved in class.

- Texting in Class - 83\% percent responded "Yes."

Finally, since this exploratory research study found that the use of social networking sites has increased, it is imperative that all social media users understand the dangers of social media and should be safe when using social media technologies.

\section{REFERENCES}

1. Ahlqvist, T., Bäck, A., Halonen, M., Heinonen, S. (2008). "Social media roadmaps exploring the futures triggered by social media." VTT Tiedotteita - Valtion Teknillinen Tutkimuskeskus (2454): 13.

2. Alexa.com. (n.d.). Top Sites by Category: Computers/Internet/On the Web/Online Communities/Social Networking. Alexa - The Web Information Company. Retrieved April 22, 2013, from http://www.alexa.com/topsites/category/Computers/Internet/On_the_Web/Online_Communities/Social_Networ king

3. Boyd, D. (2008). Why youth (heart) social network sites: The role of networked publics in teenage social life. In D. Buckingham (Ed.), Youth, Identity, and Digital Media (pp. 119-142). Cambridge, MA: MIT Press, from http://www.danah.org/papers/WhyYouthHeart.pdf

4. Boyd, D. M., \& Ellison, N. B. (2007). Social Network Sites: Definition, History, and Scholarship. Journal of Computer-Mediated Communication, 13(1), article 11, 210 - 230. Retrieved April 18, 2013, from http://www.postgradolinguistica.ucv.cl/dev/documentos/90,889,Social_network_boyd_2007.pdf

5. How to Manage Facebook's News Feed and Live Feed - For Dummies . (n.d.). How-To Help and Videos - For Dummies. Retrieved April 22, 2013, from http://www.dummies.com/how-to/content/how-to-managefacebooks-news-feed-and-live-feed.html

6. Hurt, N., Moss, G., Bradley, C., Larson, L., Lovelace, M., Prevost, L., et al. (2012). The 'Facebook' Effect: College Students' Perceptions of Online Discussions in the Age of Social Networking. www.georgiasouthern.edu. April Reved 25, 2013, from academics.georgiasouthern.edu/ijsotl/v6n2/articles/PDFs/Acc\%20Article_Hurt\%20et\%20al.pdf

7. Junco, R. (2012, January 17). College students prefer to use Facebook in their courses | Social Media in Higher Education. Social Media in Higher Education | Rey Junco's Blog. Retrieved April 26, 2013, from http://blog.reyjunco.com/college-students-prefer-to-use-facebook-in-their-courses

8. Junco, R. (2012, November 27). In-class multitasking and academic performance. Computers in Human Behavior, 28(6), 2236-2243. doi: 10.1016/j.chb.2012.06.031 http://dx.doi.org/10.1016/j.chb.2012.06.031

9. Kirschner, P. A., \& Karpinski. A. C. (2010). Facebook and academic performance. Computers in Human Behavior, 26, 1237-1245.

10. Leggetter, P. (n.d.). Phil Leggetter - Real-Time Web Software and Developer Evangelist - Real-Time Web, RealTime Data, Developer Evangelist and Consultant. Retrieved April 21, 2013, from http://www.leggetter.co.uk/2009/07/09/wikipedia-now-has-a-definition-for-real-time-web.html

11. MarketingCharts staff. (2013, March 21). 18-24-Year-Old Smartphone Owners Send and Receive Almost 4K Texts per Month. MarketingCharts: charts \& data for marketers in online, Excel and PowerPoint formats. Retrieved April 27, 2013, from http://www.marketingcharts.com/wp/direct/18-24-year-old-smartphone-ownerssend-and-receive-almost-4k-texts-per-month-27993/

12. Pinning 101. (n.d.). www.pinterest.com. Retrieved April 22, 2013, from https://about.pinterest.com/basics

13. Sunden, J. (2003). Material Virtualities: Approaching Online Textual Embodiment. New York: Peter Lang Publishing.

14. Toombs, S. (2013, March 22). The Thielensian. www.thiel.edu. Retrieved April 1, 2013, from www.thiel.edu/Thielensian/PDFs/Thielensian-03-22-13.pdf

15. Twitter.com - About. (n.d.). www.twitter.com. Retrieved April 22, 2013, from https://twitter.com/about 


\section{Issues in Information Systems}

Volume 14, Issue 1, pp.403-414, 2013

\section{APPENDIX A}

Boyd's [4] Timeline of launch dates of many major SNS and dates when community sites re-launched with SNS features.

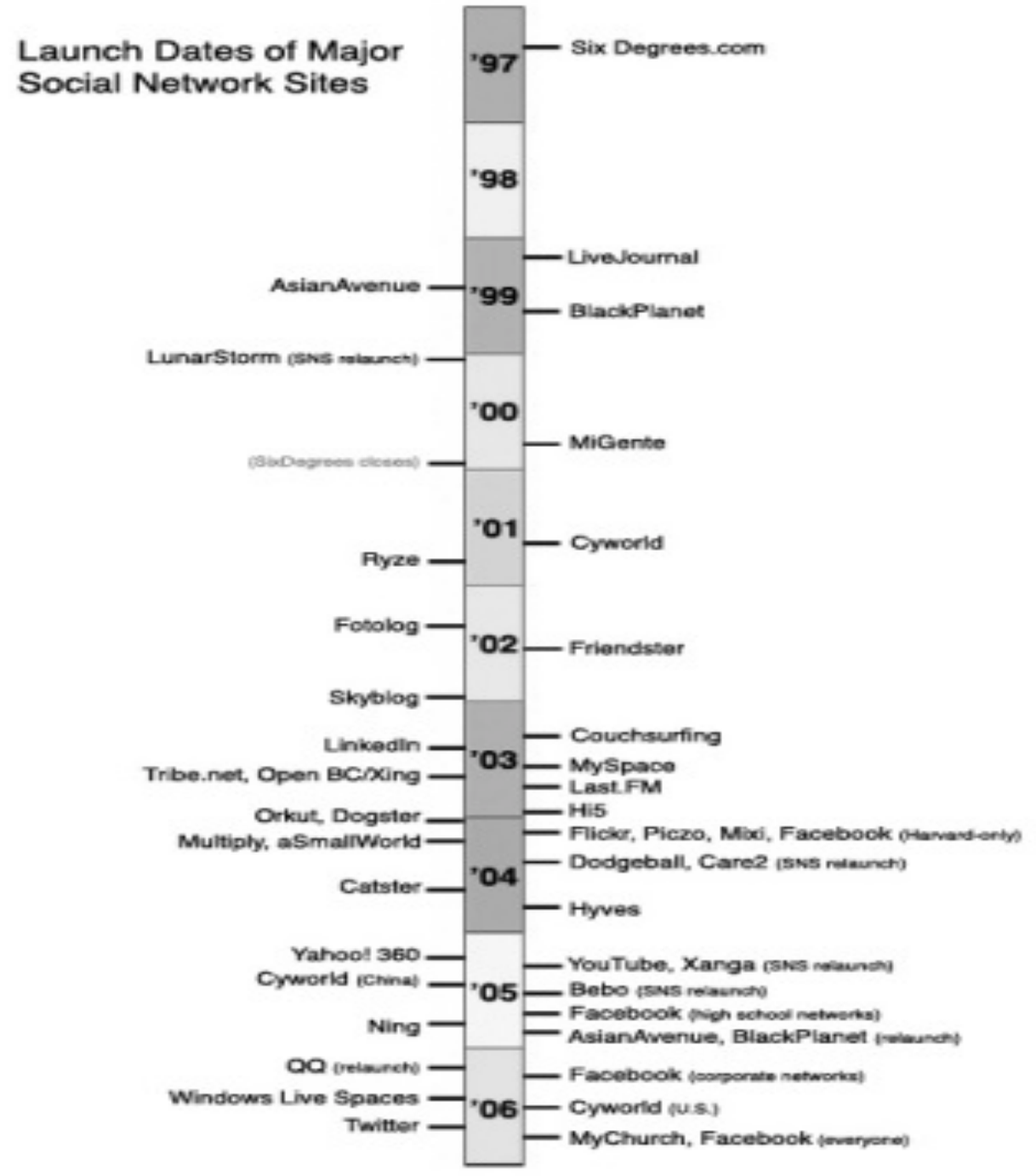




\section{Issues in Information Systems}

Volume 14, Issue 1, pp.403-414, 2013

\section{APPENDIX B}

Demographic Statistics for 2010 \& 2013

\begin{tabular}{|c|r|r|}
\hline AGE & $\mathbf{2 0 1 0}$ & \multicolumn{1}{|c|}{$\mathbf{2 0 1 3}$} \\
\hline 18 & $8.6 \%$ & $17.2 \%$ \\
\hline 19 & $24.5 \%$ & $27.0 \%$ \\
\hline 20 & $22.7 \%$ & $26.0 \%$ \\
\hline 21 & $22.7 \%$ & $16.6 \%$ \\
\hline 22 & $12.0 \%$ & $8.8 \%$ \\
\hline 23 & $4.0 \%$ & $0.3 \%$ \\
\hline 24 & $1.2 \%$ & $0.3 \%$ \\
\hline $25-30$ & $2.1 \%$ & $0.3 \%$ \\
\hline$>30$ & $1.8 \%$ & $2.4 \%$ \\
\hline
\end{tabular}

\begin{tabular}{|c|c|c|}
\hline Gender & $\mathbf{2 0 1 0}$ & $\mathbf{2 0 1 3}$ \\
\hline Male & $43.8 \%$ & $40.1 \%$ \\
\hline Female & $56.2 \%$ & $59.2 \%$ \\
\hline
\end{tabular}

\begin{tabular}{|l|r|r|}
\hline Race & \multicolumn{1}{|c|}{$\mathbf{2 0 1 0}$} & \multicolumn{1}{|c|}{$\mathbf{2 0 1 3}$} \\
\hline White, Caucasian & $81.8 \%$ & $85.9 \%$ \\
\hline White, non-Hispanic & $1.3 \%$ & $2.8 \%$ \\
\hline African-American & $8.8 \%$ & $6.0 \%$ \\
\hline Hispanic & $1.6 \%$ & $2.5 \%$ \\
\hline Asian-Pacific Islander & $6.6 \%$ & $0.4 \%$ \\
\hline
\end{tabular}

\begin{tabular}{|l|r|r|}
\hline GPA & $\mathbf{2 0 1 0}$ & $\mathbf{2 0 1 3}$ \\
\hline $\mathrm{A}(4.0 \&>)$ & $14.2 \%$ & $17.1 \%$ \\
\hline $\mathrm{A} / \mathrm{B}(3.5)$ & $34.8 \%$ & $27.2 \%$ \\
\hline $\mathrm{B}(3.0)$ & $21.2 \%$ & $28.9 \%$ \\
\hline $\mathrm{B} / \mathrm{C}(2.5)$ & $20.0 \%$ & $21.3 \%$ \\
\hline $\mathrm{C}(2.0)$ & $8.3 \%$ & $2.4 \%$ \\
\hline $\mathrm{C} / \mathrm{D}(1.5)$ & $0.3 \%$ & $1.4 \%$ \\
\hline $\mathrm{D}(1.0)$ & $0.3 \%$ & $0.3 \%$ \\
\hline Don't know & $0.9 \%$ & $0.7 \%$ \\
\hline answered question & 325 & 287 \\
\hline skipped question & 10 & 14 \\
\hline
\end{tabular}

\begin{tabular}{|l|r|r|}
\hline Major & $\mathbf{2 0 1 0}$ & $\mathbf{2 0 1 3}$ \\
\hline Accounting & $7.8 \%$ & $7.6 \%$ \\
\hline Art & $2.0 \%$ & $0.3 \%$ \\
\hline Binary Engineering & $0.3 \%$ & $1.7 \%$ \\
\hline Biology & $14.7 \%$ & $14.9 \%$ \\
\hline Business & $19.6 \%$ & $8.7 \%$ \\
\hline Chemistry & $1.6 \%$ & $3.5 \%$ \\
\hline Communications & $2.9 \%$ & $5.9 \%$ \\
\hline Computer Science & $2.6 \%$ & $3.1 \%$ \\
\hline Culinary Arts & $0.3 \%$ & $1.0 \%$ \\
\hline Criminal Justice Studies & $9.2 \%$ & $6.3 \%$ \\
\hline Cytotechnology & $0.0 \%$ & $0.0 \%$ \\
\hline E-Commerce & $0.7 \%$ & $0.0 \%$ \\
\hline Elementary Education & $6.2 \%$ & 12.1 \\
\hline English & $5.6 \%$ & $2.1 \%$ \\
\hline Environmental Chemistry or Science & $0.7 \%$ & $1.4 \%$ \\
\hline History & $2.9 \%$ & $3.1 \%$ \\
\hline Management Information Systems & $0.3 \%$ & $1.0 \%$ \\
\hline Mathematics, Actuarial Studies & $2.6 \%$ & $1.4 \%$ \\
\hline Medical Technology & $0.3 \%$ & $0.3 \%$ \\
\hline Neuroscience & $2.0 \%$ & $1.0 \%$ \\
\hline Parish Education & $0.3 \%$ & $0.0 \%$ \\
\hline Philosophy & $0.3 \%$ & $0.0 \%$ \\
\hline Physics & $1.3 \%$ & $1.0 \%$ \\
\hline Political Science & $1.6 \%$ & $3.1 \%$ \\
\hline Psychology & $11.1 \%$ & $10.4 \%$ \\
\hline Religion & $0.0 \%$ & $0.3 \%$ \\
\hline Sociology & $1.3 \%$ & $2.1 \%$ \\
\hline Web Development & $1.6 \%$ & $2.8 \%$ \\
\hline Undecided & & $1.7 \%$ \\
\hline & 306 & 288 \\
\hline & 29 & 13 \\
\hline
\end{tabular}

